\title{
Implementation of Agro-environmental Information Service System Based on WebGIS
}

\author{
Lin Peng ${ }^{1,2}$, Linnan Yang ${ }^{2, *}$, and Limin Zhang ${ }^{2}$ \\ ${ }^{1}$ College of Computer Engineering and Science, Shanghai University, 200072 \\ Shanghai, P.R. China \\ ${ }^{2}$ College of Basic Science \& Information Engineering, \\ Yunnan Agricultural University, 650201 Kunmin, P.R. China \\ dapengjiao@163.com, lny5400@sina.com, limin0789@126.com
}

\begin{abstract}
Faced to the present agro-environmental information features, there exist several difficulties to acquire and control the agricultural environment information, such as the scattered information with spatio-tempel traits, the methods of quantification and the huge data amount. This paper constructed an agro-environmental information service system based on the spatial database, computer network and geographic information system (GIS) technology. This system was applied in Jianshui County, Yunnan to implement the system functions including the collection, storage, analysis, visual output and intelligent evaluation. The system with these functions applied technical support for Jianshui county to improve the abilities both in local agricultural products and environmental protection. And it provided a precedent for other Counties in Yunnan to construct agricultural environmental information system.
\end{abstract}

Keywords: WebGIS, Agricultural environment, Information service system, Spatial database.

\section{Introduction}

Both of the qualities and the quantities of agricultural products are the most important aspects for farmers, agricultural technicians and managements. In modern agricultural processes, how to improve the products' qualities is much more increasingly come into people's attention than to improve the quantities. And the qualities of the agricultural products include many strict standards such as pollution-free food standards and green food standards etc. In order to meet these standards, the basic step is to monitor and protect agricultural ecology environment because there is impossible to gain any high quality agricultural products from heavy polluted air, soil and water.

Any environment protection measure would be blind if there is no monitor to gain plenty of quantification environment information. Only though the environment monitoring to acquire appropriate environment information data could understand the reasons why the pollutions created and the regularities that the pollutions changed. Then these reasons and regularities are significant for agricultural 
technicians and managements to formulate practical environment protection plans. Thus, contemporary computer technologies were be used frequently to obtain temporal and spatial ago-environmental information in different scales. But since agricultural environment information is scattered and indirect, it is difficult to use the obtained information data fully to promote environment protecting level [1].

And all of these problems are particularly realistic in Yunnan Province, which is located in the southwest of China. The land in Yunnan is varied from mountain on Yungui Plateau at the altitude of 6740 meters to valley at the altitude of 76 meters. The prominent disparity of altitude arouses multiple land forms and complex climates. This unique geographical environment imposed diversification on Yunnan agricultural structure, and increased the difficulties in environment monitoring for agricultural workers, technicians and managements.

This paper aimed at obtained environment monitoring data from 2005 to 2009 in Jianshui County, Yunnan designed and implemented a new agro-environmental information service system based on WebGIS. Firstly, the relative agro-environmental information data were aggregated and classified such as atmosphere information, soil information, heavy metal information in soil, irrigation water information. Secondly, the agro-environmental information service system was designed based on the technologies including computer, spatial database, network, and geographical information system (GIS). Compared with the used information service system this new system implemented inquiry, modification, addition and deletion etc. operations on mass environmental information data, and applied the local farmers directly, visually and comprehensively agro-environmental information service. The new system integrated agro-environmental information data and corresponding evaluation model to implement intelligent evaluations on the environmental pollution levels including air, water, soil and soil fertility.

\section{System Design}

\subsection{System Development Methodology}

First, attribute database was built based on collected data such as environmental quality standards, atmosphere data, fertility data of soil, heavy metal data of soil, irrigation water data and so on according to the investigation in Jianshui.

Second, spatial database was built according to the administrative map of Jianshui and some spatial data such as land form data, monitoring spot data, pollution elements data in soil and so on. And profile the corresponding digital map of these spatial data at the same time.

Third, a multi-index evaluation model was developed based on the above attribute database and spatial database to analyze the contamination degree of the air, water, soil and the soil fertility level. The evaluation model was integrated into WebGIS Components and could be used by consumers. The technique flow diagram of the system development was illustrated in Fig.1. 
Vector data base and raster dat abase

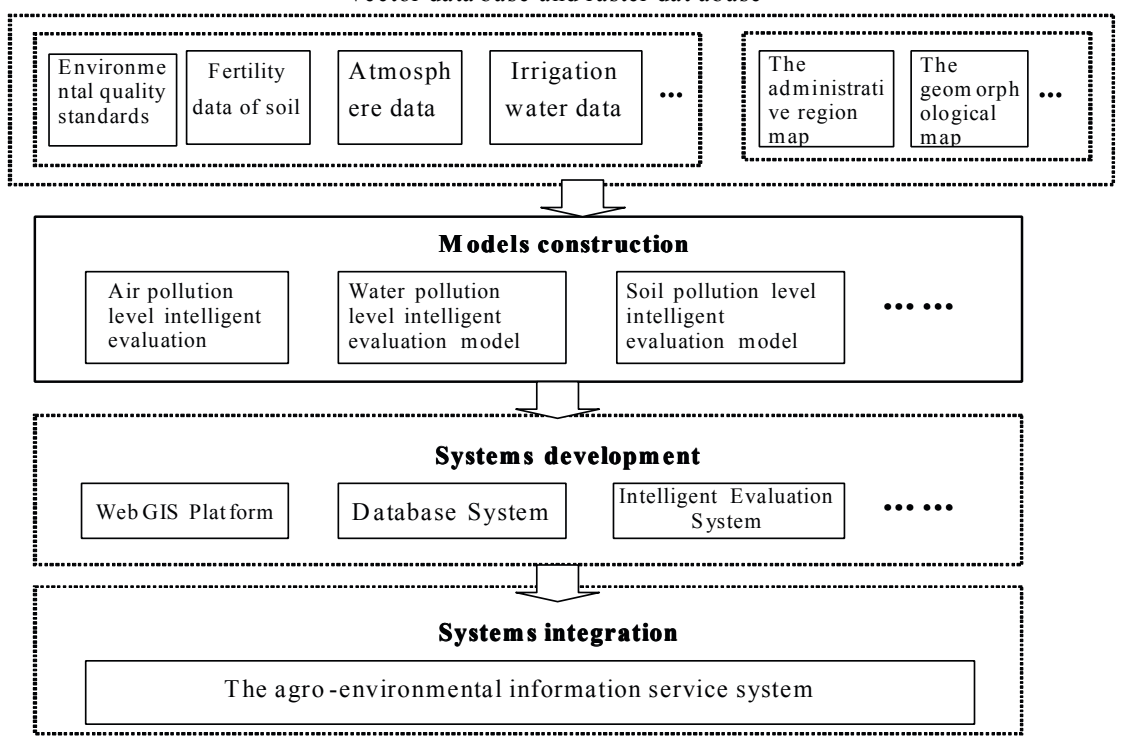

Fig. 1. Technique flow diagram of the system development

\subsection{System Development Platform}

The agro-environmental information service system is built on the network technical architecture, so this paper integrated the network and GIS technology to develop and implement a practical agro-environmental information service system in Jianshui, Yunnan.

SuperMap IS.NET was chosen to be the development platform in the new information service system, because the function and structure of SuperMap IS.NET WebGIS platform could satisfy the system development requirements which should be completed with compatibility, expansion, generalized data exchange format. And SuperMap Deskpro5 was chosen to be the plotting software to draw electronic map to improve the equipment compatibility because both of the SuperMap IS.NET and SuperMap Deskpro5 are the products from the same software company. At the same time, since the system would face the challenge of mass data storages and operations, SQL Server 2005 was used as system database development tool to solve the expansion and integration difficulties of the system database.

\section{The Implementation of the System}

\subsection{System Structure}

Architecture. B/S/D (Browser/Service/Database) three-layer architecture was used to implement the design and development of the system expandable, make the system module components reusable, and make the system services independent. 


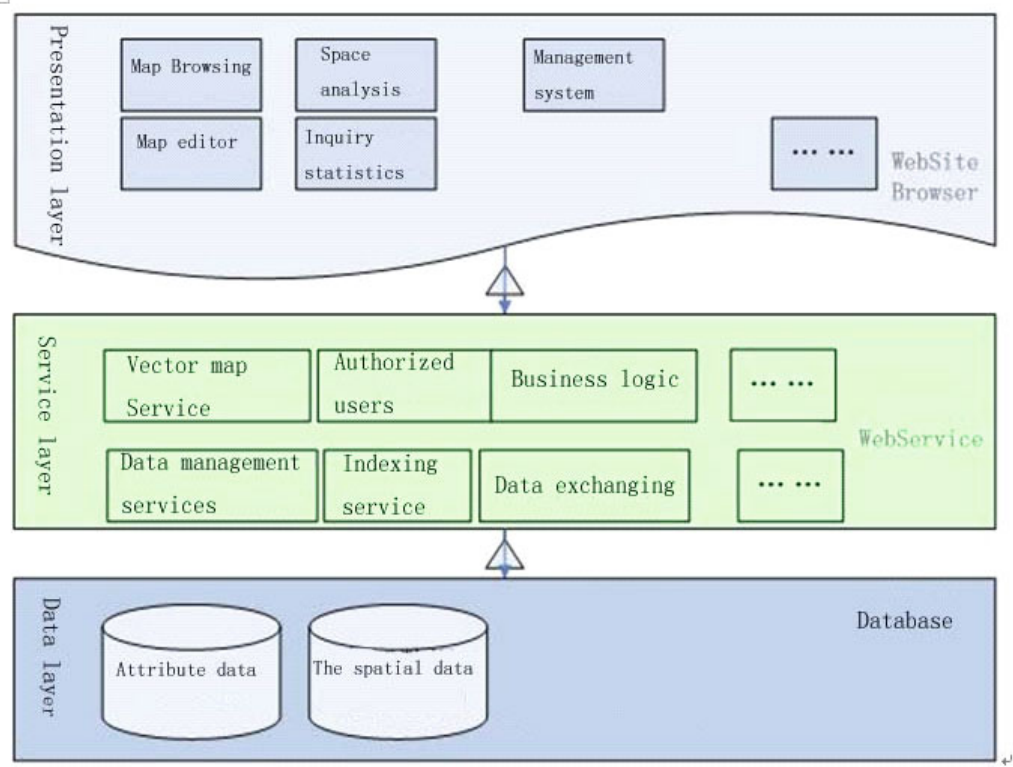

Fig. 2. Architecture diagram of the system

(1) Database Layer

SQL server database software was used as supporting software in database layer. All the designs included five spatial databases. They were spatial database of production resources information, spatial database of soil fertility information, spatial database of soil pollution information, spatial database of irrigation water information and spatial database of climate information spatial database.

\section{(2) Service Layer}

SuperMap IS 2008 was used in Service layer to support the map generation and management functions.

\section{(3) Browser Layer}

IE6.0 or above version was adopted to be the browser to develop the website. Web controls were used to invoke both of the services in the Service Layer and the User Interface. Browser layer has the functions of browsing map, editing map, spatial Analysis, query statistics, etc.

Network Structural. Network structural designing mainly resolved two problems:

(1) How to access different server

(2) How to meet the requirements of different access pressure. 


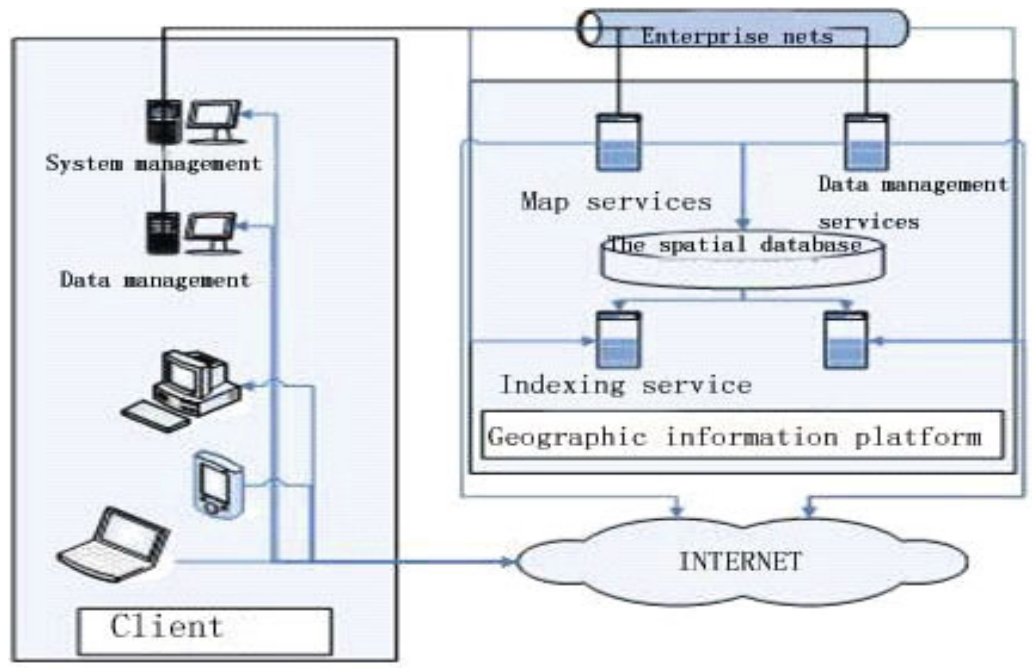

Fig. 3. Network structure diagram of the system

\subsection{The Data Arrangement}

Data analysis. There were two types of data in this system, vector data and raster data. The data design and the analysis were showed in Fig. 4.

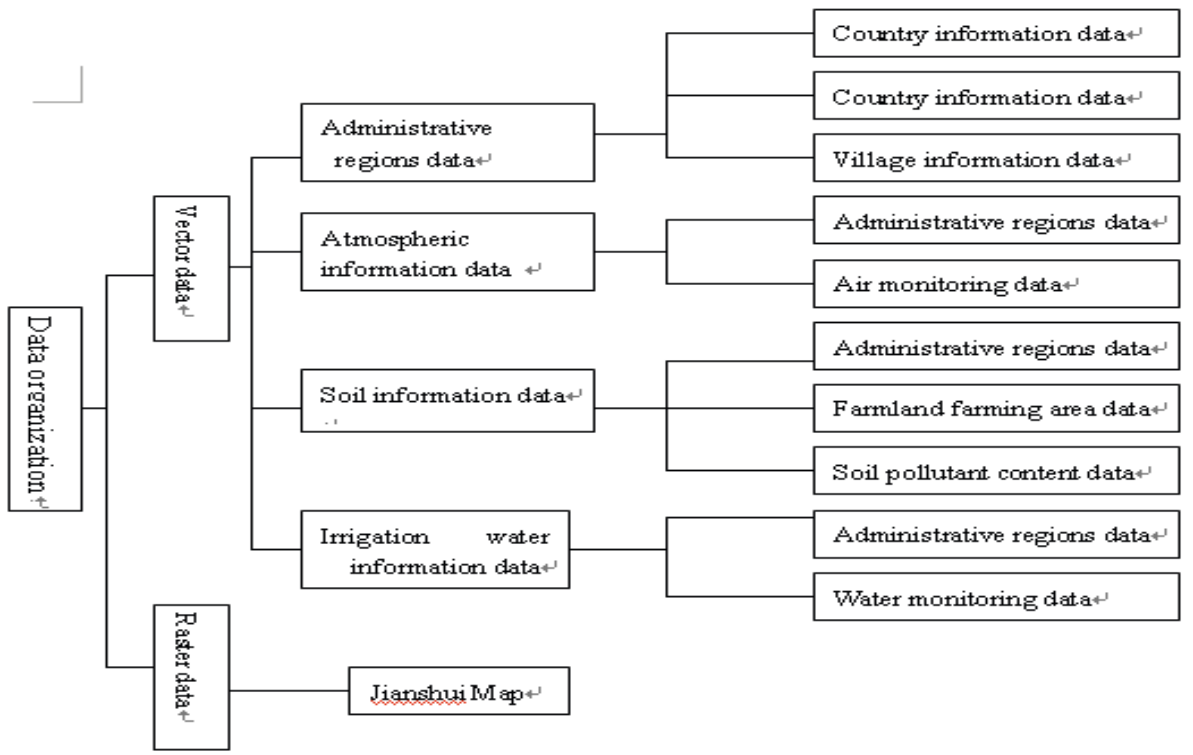

Fig. 4. Data analysis diagram of the system 
With the assistance of Jianshui Agricultural Bureau, chose 10 villages in 3 towns, they are Lin'an, Miandian and Puxiong in Jianshui, to be the investigation sites. Then, the agro-environmental information, which included atmosphere data, irrigation water data and soil data in these 10 villages were collected according to national environmental requirements on agricultural products base. Among these national standard, this system adopted GB5084-92 national standard on farm irrigation water, GB 3095-1996 national standard on atmosphere, and GB15618-1995 national standard on soil.

The collected data mainly includes geospatial information data and attribute data.

(1) Geospatial information data

The geospatial information data is stored in 'eoo' format based on the administrative region map in Jianshui at 1: 50000.

(2) Attribute data

The attribute data included main environmental information from 2005 to 2009, such as air data, irrigation water data, soil data, planted area data and other basic data. These data were provided by the Jianshui Agricultural Bureau from Status Survey on Agro- environmental in JianShui.

The soil database sample was showed in table 1.

Table 1. Air pollution Index data

\begin{tabular}{|c|c|c|c|c|c|c|c|c|c|c|c|c|c|c|}
\hline Recervolr & $\mathbf{F H}$ & Copper & Zine & Norroury & Arecuite & ar $\mathbf{I}$ & $\begin{array}{l}\text { flumer of } \\
\text { Colifere }\end{array}$ & Mouride & 011 type & $\infty$ & Crenide & Iotal-P & Phomol & $\begin{array}{l}\text { Total } \\
\text { ealt }\end{array}$ \\
\hline Laohongshan & 8.14 & 0.003 & 0.001 & 0.00005 & 0.0005 & 0.002 & 150 & 0.18 & 0.2207 & 34.4 & 0.002 & 0.012 & 0.002 & 116 \\
\hline Xizaotang & 7.7 & 0.006 & 0.001 & 0.00005 & 0.0005 & 0.007 & 180 & 0.18 & 0.3908 & 31.9 & 0.002 & 0.021 & 0.002 & 338 \\
\hline Tachong & 8.05 & 0.004 & 0.012 & 0.00005 & 0.0005 & 0.007 & 200 & 0.16 & 0.7644 & 36.9 & 0.002 & 0.014 & 0.002 & 91 \\
\hline Tianhuashan & 8.04 & 0.006 & 0.02 & 0.00005 & 0.0005 & 0.008 & 210 & 0.17 & 1. 1646 & 47 & 0.002 & 0.012 & 0.002 & 183 \\
\hline Mianyangshan & 7.28 & 0.004 & 0.012 & 0.00005 & 0.0005 & 0.008 & 220 & 0.11 & 0.8211 & 9.2 & 0.002 & 0.014 & 0.002 & 112 \\
\hline Baijiatian & 7.87 & 0.004 & 0.006 & 0.00005 & 0.0005 & 0.008 & 120 & 0.07 & 0.2726 & 16. 3 & 0.002 & 0.028 & 0.002 & 141 \\
\hline Yuejin & 7.67 & 0.004 & 0.019 & 0.00005 & 0.0005 & 0.009 & 150 & 0.13 & 0.5184 & 15.8 & 0.002 & 0.03 & 0.002 & 178 \\
\hline
\end{tabular}

The irrigation water database sample was showed in table 2 . 
Table 2. Water pollution Index data

\begin{tabular}{|c|c|c|c|c|c|c|c|c|c|c|c|}
\hline Village & PH & $\begin{array}{r}\text { Organic } \\
\mathbf{g} / \mathbf{K g}\end{array}$ & $\begin{array}{l}\text { c Total-N } \\
(\mathbf{N}) \mathrm{g} / \mathrm{Kg}\end{array}$ & $\begin{array}{l}\text { Effective } \\
(\mathrm{N}) \mathrm{mg} / \mathrm{Kg}\end{array}$ & Total-P & $\begin{array}{l}\text { Effective } \\
(\mathrm{P}) \mathrm{mg} / \mathrm{Kg}\end{array}$ & Total-K & $\begin{array}{l}\text { Effective } \\
(\mathrm{K}) \mathrm{mg} / \mathrm{Kg}(\end{array}$ & $\begin{array}{c}\text { Effective } \\
(\mathrm{Zn}) \mathrm{mg} / \mathrm{Kg}\end{array}$ & $\begin{array}{c}\text { Effective } \\
(\mathbf{M n}) \mathrm{mg} / \mathbf{K g}\end{array}$ & $\begin{array}{l}\text { Effective } \\
\text { (B) } \mathrm{mg} / \mathrm{Kg}\end{array}$ \\
\hline Maliaohe & 8.00 & 34.22 & 1.87 & 128.89 & 1.72 & 42.00 & 16.37 & 172.37 & 13.10 & 0.57 & 0.14 \\
\hline Yanbasi & 6.57 & 128.47 & 3.28 & 118.48 & 1.29 & 109.83 & 7.19 & 10.96 & 1.22 & 2.17 & 0.32 \\
\hline Tala & 6.71 & 33.40 & 1.59 & 111.87 & 1.24 & 7.64 & 4.16 & 294.30 & 15.40 & 0.14 & 0.19 \\
\hline Xihu & 7.40 & 34.89 & 1.45 & 144.90 & 0.73 & 24.70 & 17.86 & 95.87 & 2.20 & 3.19 & 0.21 \\
\hline Peide & 6.90 & 19.46 & 1.26 & 88.68 & 0.48 & 31.34 & 9.19 & 89.35 & 0.17 & 0.41 & 0.12 \\
\hline Zhongsuo & 7.10 & 16.84 & 1.37 & 100.79 & 0.13 & 40.32 & 15.48 & 131.00 & 0.09 & 0.27 & 0.10 \\
\hline Majun & 7.90 & 25.50 & 1.71 & 111.40 & 0.95 & 59.30 & 31.80 & 23.7 & 3.36 & 2.03 & 0.18 \\
\hline Chengjiao & 8.00 & 25.27 & 1.31 & 13.23 & 0.49 & 7.78 & 4.98 & 74.47 & 3.58 & 2.14 & 0.60 \\
\hline Fuqiao & 7.48 & 21.90 & 1.40 & 118.03 & 1.38 & 70.89 & 11.20 & 64.00 & 2.40 & 10.09 & 0.66 \\
\hline Mawang & 7.94 & 79.10 & 3.96 & 290.46 & 1.86 & 48.65 & 14.15 & 143.60 & 6.86 & 8.01 & 0.69 \\
\hline
\end{tabular}

The soil heavy metal database sample is showed in table 3 .

Table 3. Soil pollution Index data

\begin{tabular}{|c|c|c|c|c|c|c|c|c|c|}
\hline \multirow{2}{*}{ Identifier } & \multirow{2}{*}{ Village } & \multicolumn{6}{|c|}{ Single pollution index } & \multirow{2}{*}{ comprehensive } & \multirow{2}{*}{ conclusion } \\
\hline & & $\mathbf{C u}$ & $\mathbf{P b}$ & Cd & $\mathbf{H g}$ & As & $\mathbf{C r}$ & & \\
\hline T20050484 & Wanyao & 0.74 & 0.95 & 0.54 & 0.44 & 0.84 & 0.58 & ------- & $\mathrm{T}$ \\
\hline T20050485 & Wanyao & 1.71 & 1.17 & 0.44 & 0.24 & 0.33 & 0.38 & 1.31 & $\mathrm{~F}$ \\
\hline T20050486 & Ganhe & 0.74 & 1.11 & 0.21 & 1.25 & 1.92 & 1.18 & ------- & $\mathrm{F}$ \\
\hline T20050487 & Ganhe & 0.94 & 1.38 & 0.59 & 0.99 & 2.27 & 1.31 & ------ & $\mathrm{F}$ \\
\hline T20050488 & Xihu & 1.11 & 1,79 & 0.52 & 0.21 & 3.13 & 1.65 & ------ & $\mathrm{T}$ \\
\hline T20050489 & Dongcun & 0.92 & 2.38 & 0.62 & 0.57 & 0.61 & 0.78 & 1.82 & $\mathrm{~F}$ \\
\hline T20050490 & Goujie & 0.82 & 0.97 & 0.40 & 1.00 & 2.51 & 1.78 & ------- & $\mathrm{F}$ \\
\hline T20050491 & Dongcun & 1.42 & 2.96 & 0.90 & 1.70 & 3.30 & 1.83 & ------- & F \\
\hline T20050492 & Peide & 0.81 & 0.94 & 0.34 & 0.28 & 0.97 & 0.82 & ------- & $\mathrm{T}$ \\
\hline T20050493 & Fengjia & 0.72 & 0.89 & 0.34 & 0.34 & 1.35 & 0.81 & ------ & F \\
\hline T20050494 & Luobodian & 1.42 & 0.59 & 0.52 & 0.14 & 0.24 & 2.98 & ------- & $\mathrm{F}$ \\
\hline
\end{tabular}

Database design. The database in this system was divided into two parts: spatial database and non-spatial database. Spatial database was stored in 'sde' database with SQL Server format. And the special layer information in the spatial data included administrative region map, contour map, land utilization map and geomor-phological map in Jianshui.

Non-spatial database contained four types of ago-environmental information: atmosphere database, soil database, soil heavy metal database, irrigation water database.

Among these databases, there were 9 field names in atmosphere database; they were average geo-temperature, average air-temperature, lowest air temperature, highest air temperature, average wind speed, average relative humidity, sunshine duration, evaporation and precipitation. 
There were 14 field names in soil database; they were $\mathrm{PH}$ value, organic horizon $(\mathrm{g} / \mathrm{kg})$, total nitrogen $(\mathrm{N}) \mathrm{g} / \mathrm{kg}$, available nitrogen $(\mathrm{N}) \mathrm{mg} / \mathrm{kg}$, total phosphorus $(\mathrm{P}) \mathrm{g} / \mathrm{kg}$, available phosphorus $(\mathrm{P}) \mathrm{mg} / \mathrm{kg}$, total potassium $(\mathrm{K}) \mathrm{g} / \mathrm{kg}$, quick-acting potassium $(\mathrm{K})$ $\mathrm{mg} / \mathrm{kg}$, slow-acting Potassium(K)mg/kg, exchangeable magnesium( $\mathrm{Mg}) \mathrm{g} / \mathrm{kg}$, available molybdenum(Mo)mg/kg, available zinc( $\mathrm{Zn}) \mathrm{mg} / \mathrm{kg}$, available manganese(Mn) $\mathrm{mg} / \mathrm{kg}$ and available boron(B) $\mathrm{mg} / \mathrm{kg}$.

There were 6 field names in soil heavy metal database; they were copper, lead, mercury, cadmium, chrome and arsenic.

There were 17 field names in irrigation water database; they were $\mathrm{PH}$ value, cadmium, lead, copper, zinc, mercury, arsenic, chrome, dung coliform group, fluoride, chloride, petroleum, COD, cyanide, total phosphorus, volatile phenol and salt.

\subsection{Function Design}

Function Design in this System contained 6 main function modules: graphics operation function, spatial data orientation function, environmental data query and analysis function, attribute data maintenance function, processing function on the monitoring data and intelligent evaluation function.

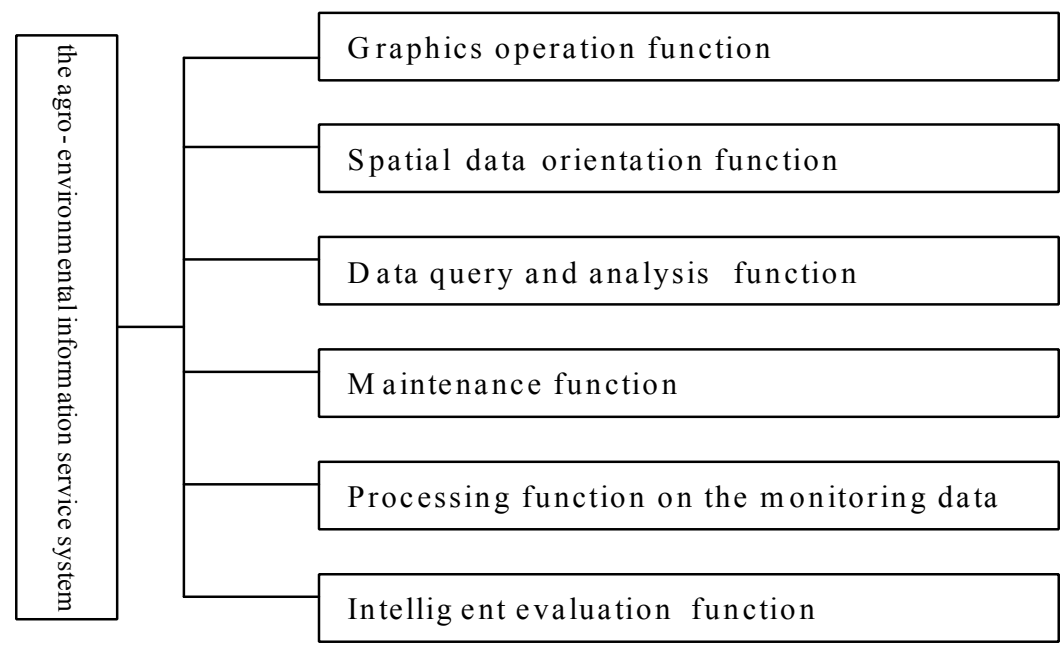

Fig. 5. Functional structure diagram of the system

(1) Graphics operation function.

Jianshui map could be operated with any common browsers. The system could realize zoom in, zoom out, pan, fix zoom, full screen display, roaming, Hawkeye, guidance and other functions. 
(2) Spatial data orientation function.

The spatial orientation function could be achieved in electronic map by click, marquee selecting or other query operations.

(3) Data query and analysis function.

The accurately or fuzzy query could be achieved both on spatial data and attribute data. And all users could gain detail information of the selected objects by mouse click or marquee on the electronic map.

(4) Maintenance function.

The system databases could be edited remotely by the system administrators though background operation, which included adding or deleting entity objects and layers, modifying the space position and attribute data of the entity objects and other functions.

(5) Processing function on the monitoring data

This new system carried out detailed statistical analysis functions on the obtained spatial and attributes data by WebGIS system. Such as shortest path analysis function, distance and area measurement function, statistical graph generation function of the attribute data and others.

(6) Intelligent evaluation function.

The pollution degree of the ago-environment factors (air, water, soil and soil fertility etc.) could be evaluated intellectually according to the corresponding national standards.

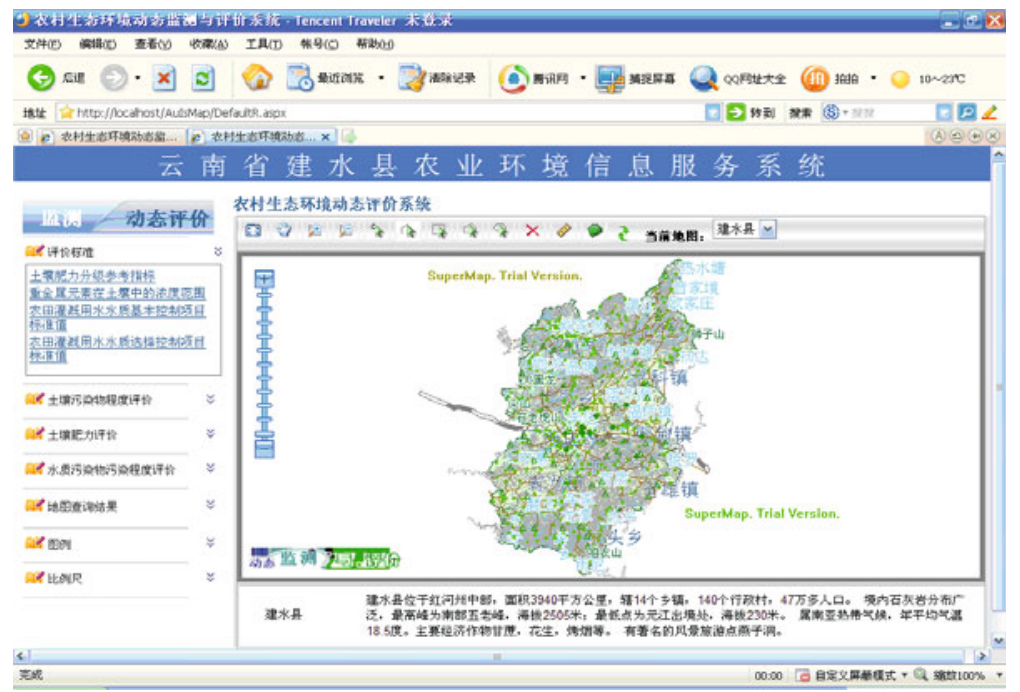

Fig. 6. The interface of running intelligent evaluation function 


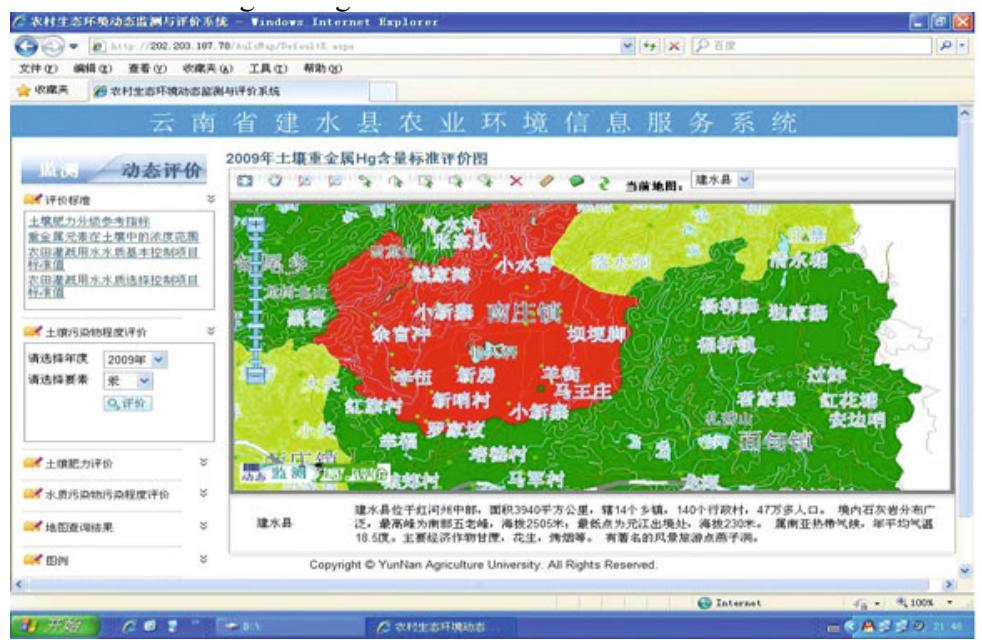

Fig. 7. The interface of rendering image of mercury content in soil pollutant

\section{Conclusions}

This paper introduced the designing methods and implication of the agroenvironmental information service system based on WebGIS in Jianshui county, Yunnan in details. The relative environmental data were converged together including atmosphere data, soil data, soil heavy metal data, farm irrigation water data etc. in the new system and it offered the costumers a brief and direct interface to obtain valuable agro-environmental information and geospatial information in Jianshui. Besides providing the information inquiring, this system achieved spatial inquire, analyze, and plotting functions between the graphics and attribute data. And also, the new system could accomplish intelligent evaluation on environmental pollution levels, including air pollution, water pollution, soil pollution and soil fertility levels.

The new agro-environmental information service system was applied successfully in Jianshui County. Local agricultural worker, technicians and managements could obtain agricultural or environmental information accurately and directly in time by the system. And the system design process offered other Counties in Yunnan a valuable method and a precedent to build suitable agro-environmental information service system.

Acknowledgments. The findings and the opinions were partially supported by a project of Natural Science Foundation of Yunnan Province __ "Design and implementation of county agro-environmental information service system based on WebGIS", NO. 2008ZC050M. This work was supported by Shanghai University, China and Yunnan Agricultural University, China. 


\section{References}

1. Yan, L.F., Xie, Y.S.: The Study on the County Land Information System. Soil and Water Conservation Science and Technology in Shanxi 1, 10-12 (2004)

2. Rao, W.M., Zhang, J.S., Xiao, H.S.: Reviews on Present Situation of GIS Application in Agriculture. Yun Nan Geographic Environment Research 16, 13-17 (2004)

3. Li, Z.P., Li, M., Wu, M.: Design and Realization of Digital Pipeline System based on WebGIS. Computer Engineering and Applications 45, 70-72 (2009)

4. Wang, P.S., Zou, Z.R., Weng, Y.K.: Research and Implementation of Flood Prevention and Dispatching System Based on WebGIS for the Yangtze River Valley. Geomatics \& Spatial Information Technology 32, 118-120 (2009) 